\title{
Transient expression of the Arabidopsis thaliana callose synthase PMR4 increases penetration resistance to powdery mildew in barley
}

\author{
Antje Blümke ${ }^{1}$, Shauna C. Somerville ${ }^{2}$, Christian A. Voigt ${ }^{1,2^{*}}$ \\ ${ }^{1}$ Phytopatholgy and Biochemistry, Biocenter Klein Flottbek, University of Hamburg, Hamburg, Germany \\ ${ }^{2}$ Energy Biosciences Institute, University of California, Berkeley, USA \\ Email: ${ }^{*}$ christian.voigt@uni-hamburg.de
}

Received 1 May 2013; revised 12 June 2013; accepted 9 July 2013

Copyright (C) 2013 Antje Blümke et al. This is an open access article distributed under the Creative Commons Attribution License, which permits unrestricted use, distribution, and reproduction in any medium, provided the original work is properly cited.

\begin{abstract}
Localized cell wall thickenings, so called papillae, are a common plant defense response to fungal attack at sites of penetration of the plant cell. The major constituent of papillae is callose, a $(1,3)-\beta$-glucan polymer, which contributes to slowing or blocking the invading fungal hyphae. In the model plant Arabidopsis thaliana, we could recently show that the overexpression of PMR4 (POWDERY MILDEW RESITANT 4), which encodes a stress induced callose synthase, results in complete powdery mildew resistance. To evaluate if these findings are also transferable to monocot crops, we transiently expressed PMR4 under control of the 35S promoter in leaves of barley (Hordeum vulgare) seedlings, which were subsequently inoculated with the virulent powdery mildew Blumeria graminis f. sp. hordei. Fusion of the green fluorescent protein (GFP) to PMR4 allowed the identification of successfully transformed barley cells, which showed an increased penetration resistance to $B$. graminis compared to control cells that express only GFP. PMR4-GFP localized in a similar pattern at the site of attempted fungal penetration as observed in $\boldsymbol{A}$. thaliana, which suggests that similar transport mechanisms of the callose synthase might exist in dicot and monocot plants.
\end{abstract}

Keywords: Biotic Stress; Callose; Glucan; Fungal Resistance; Plant Defense; Plant Engineering

\section{INTRODUCTION}

The plant cell wall is one of the first lines of defense against invading pathogens. A strengthening of the cell

\footnotetext{
"Corresponding author.
}

wall by callose deposition in so called papillae is considered as an important part of the basal plant resistance mechanism against penetration [1]. Callose is a linear polysaccharide, which consists of $(1,3)-\beta$-linked glucose monomers with some $(1,6)-\beta$-branches [2]. It is synthesized by membrane-bound callose synthases [3], which might be organized in multiprotein complexes [4] and use UDP-glucose as substrate [5]. In Arabidopsis thaliana, 12 callose synthase genes are described [4]. They showed a tissue-specific expression [6], which was also reported from callose synthase genes in wheat [7]. Among the 12 callose synthases in A. thaliana, PMR4 (POWDERY MILDEW RESITANT 4, also called GLUCAN SYNTHASE LIKE 5) is responsible for woundand pathogen-induced callose formation [8,9]. Interestingly, PMR4 did not seem to be required for penetration resistance to powdery mildew in the A. thaliana mlo2 (MILDEW RESISTANCE LOCUS O 2) mutant [10], whereas an inhibition of callose synthesis in a barley (Hordeum vulgare) mlo mutant resulted in an increased powdery mildew penetration [11]. Because callose inhibition studies with wheat (Triticum aestivum) and oat (Avena sativa) show similar effects after callose inhibition [12], it is suggested that callose deposition might have a function in penetration resistance that is more important in monocot than dicot plants. However, we could recently demonstrate that callose deposition can also play a major role in powdery mildew resistance in $A$. thaliana. The overexpression of PMR4 in A. thaliana led to an early enhanced callose deposition after powdery mildew infection, which conferred complete penetration resistance $[3,13]$. Based on the scientific and economic importance of powdery mildews and especially Blumeria graminis [14], we wanted to evaluate whether modification of callose biosynthesis would also increase penetration resistance to an adapted powdery mildew in barley. 


\section{MATERIALS AND METHODS}

\subsection{Transient Expression}

For barley transformation, we used a binary vector that contains the cassette $35 S:: P M R 4-G F P$ for overexpression of the A. thaliana callose synthase PMR4 fused to the green fluorescent protein GFP under control of the constitutive cauliflower mosaic virus promoter $35 \mathrm{~S}$ [3]. As a control, we generated a binary vector for $35 \mathrm{~S}$-controlled GFP overexpression. The GFP open reading frame was amplified from pIGPAPA [15] using an NcoI-containing 5' and a Bst EII-containing 3' primer. The NcoI-Bst EII-digested GFP fragment was cloned into the likewise prepared vector pCAMBIA3301 (Cambia, Australia), which supplied a $35 \mathrm{~S}$ promoter element upstream to the GFP cloning site. The primer sequences are: GFP-fw [5'GCCATGGTGAGCAAGGGCGAG] and GFP-rev [5'GGGTGACCTTACTTGTACAGCTCGTCC]. The two vectors were transformed into the bacterium Agrobacterium tumefaciens (strain GV3101). To analyze whether strong powdery mildew resistance could also be induced in crops, we transiently expressed the $35 S:: P M R 4-G F P$ and $35 S:: G F P$ construct in barley leaves. The respective A. tumefaciens suspensions were infiltrated into leaves of 12-day-old barley seedlings (line Algerian-S (CI-16138)) as described for rice [16].

\subsection{Barley Leaf Infection and Microscopy}

$24 \mathrm{~h}$ post-infiltration, leaves were inoculated with $B$. graminis f. sp. hordei ( $B g h$, race CR3) as described for $A$. thaliana [17] and monitored at $15 \mathrm{~h}$ post-inoculation (hpi), when haustorium formation by Bgh indicates successful penetration in this susceptible barley line [18]. Barley as well as the powdery mildew Bgh were cultivated as described in Stein et al. [17]. Leaf samples were mounted between two cover slips in water. $\mathrm{Z}$ series were captured with a spinning-disk confocal microscope [19] by using a Leica $63 \times$ water-immersion objective. For better visualization of the fungal conidia and hyphae, the samples were stained with propidium iodide. GFP and propidium iodide were excited at $488 \mathrm{~nm}$ by using an argon laser. Emission filtering for GFP was done with a $520 / 50$, for propidium iodide with a $570-650 \mathrm{~nm}$ bandpass filter. 2D projections of $\mathrm{Z}$ stacks were produced with ImageJ (Rasband, W.S., US National Institutes of Health, Bethesda, Maryland, USA, http://imagej.nih.gov/ij/, 1997-2011).

\section{RESULTS AND DISCUSSION}

Microcopy of infiltrated leaves revealed that the efficiency of $A$. tumefaciens-mediated transient expression was relatively low. At $24 \mathrm{~h}$ post-infiltration, only 1 out of 136 cells ( \pm 17 cells) showed a GFP signal in $35 S:: G F P$ control leaves, whereas GFP signals were not detectable in leaves infiltrated with the $35 S:: P M R 4-G F P$ construct before powdery mildew inoculation (Figure 1(a)). The leaves were then inoculated with the barley powdery mildew Bgh. To increase the coincidence of GFP-expression and an infection of the same cell, spore density was set to 65 conidia $\cdot \mathrm{mm}^{-2}$. We determined penetration success by haustoria formation in epidermal cells $15 \mathrm{hpi}$ by using confocal laser-scanning microscopy to additionally identify $P M R 4-G F P$ - and $G F P$-expressing cells, which were infected by $B g h$. At $15 \mathrm{hpi}$, GFP-signals also occurred in 35S::PMR4-GFP-infiltrated leaves at sites of attempted fungal penetration (Figure 1(a)). The pattern of the GFP-signal was similar to the signal detected in the $A$. thaliana $35 S:: P M R 4-G F P$ mutants after $G$. cichoracearum infection; a dense core with a surrounding field of lower density [3,13].

Quantification of microscopy images revealed that in untreated barley leaves, $85 \%$ of germinated conidia were able to penetrate as determined by haustorium formation, which is in the range of reported penetration rates for $B g h$ on susceptible barley lines [18,20]. Buffer-infiltration reduced penetration success to $70 \%$ (Figure 1(b)). Counting the overall penetration success in A. tumefaciens-infiltrated barley leaves, a difference to bufferinfiltrated leaves was not detectable. Penetration success in cells with distinct $P M R 4-G F P$ presence at the site of $B g h$ penetration was significantly reduced to $36 \%$, whereas simple GFP presence in infected cells did not alter Bgh penetration (Figure 1(b)).

Our results show that modification of callose biosynthesis can increase resistance to adapted powdery mildew in a monocot plant. The basis for the resistance seems to be similar as recently described for A. thaliana, the focal accumulation of the callose synthase at the site of attempted fungal penetration [3]. Interestingly, barley was able to focally accumulate the callose synthase PMR4 from the different, dicot plant species $A$. thaliana at the fungal penetration site. This suggests that transport mechanisms that are involved in stress-induced callose deposition as a defense response to pathogens might be conserved in plants. A stable overexpression of the callose synthase PMR4 would further improve microscopy, which would help to elucidate these regulatory mechanisms. One aim could be to evaluate whether already known regulatory factors of stress-induced callose biosynthesis, like the GTPase ARFA [21], are also involved in the PMR4-based resistance to powdery mildew in barley. In addition, a stable overexpression of the callose synthase would also facilitate the determination of possible alterations in the cell wall composition.

In $A$. thaliana, the overexpression of PMR4 induced changes in the noncellulosic monocarbohydrate composition, especially reflected by the increase in the amount 


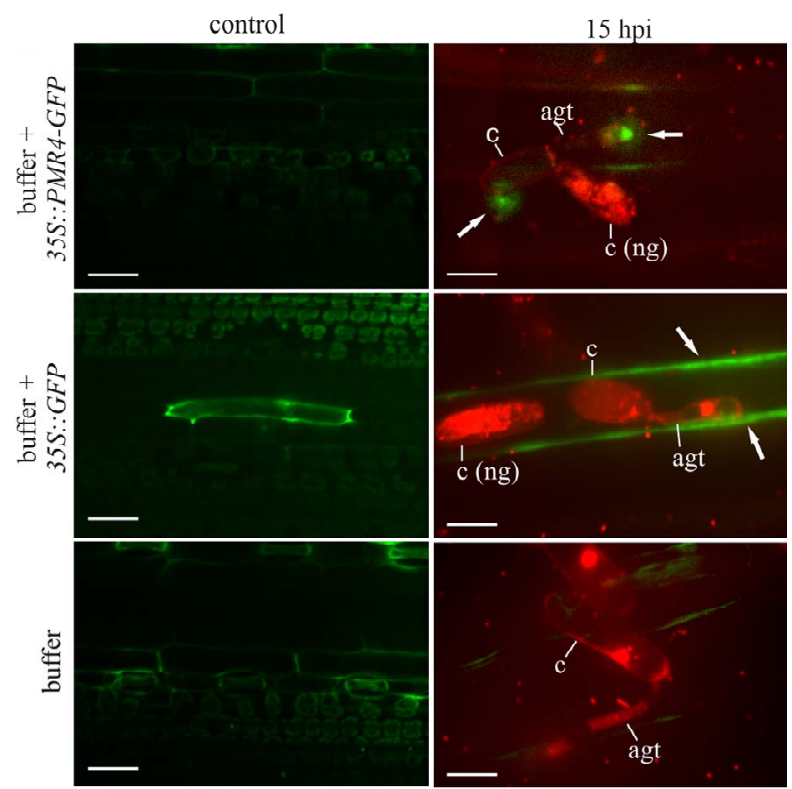

(a)

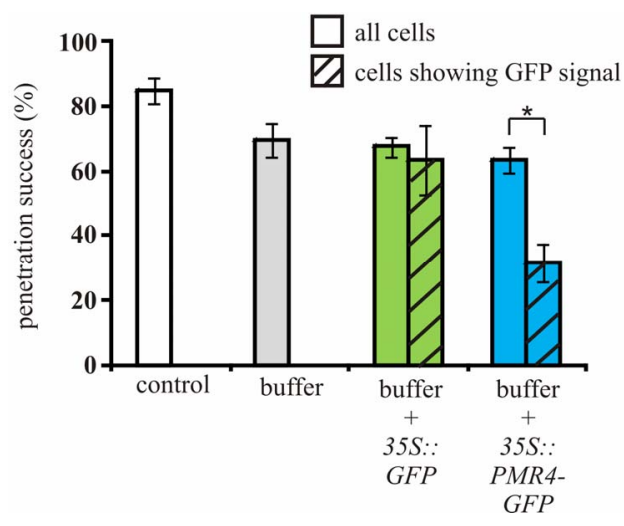

(b)

Figure 1. Transient $P M R 4-G F P$ expression confers elevated resistance to powdery mildew in barley leaves. (a) Z-projected micrographs from confocal laser-scanning microscopy (cLSM) of 12-day-old barley seedling leaves infiltrated with Agrobacterium suspensions containing constructs $35 S:: P M R 4-$ $G F P$ and $35 S:: G F P$ and buffer only. $24 \mathrm{~h}$ post-infiltration, leaves were screened for GFP-based fluorescence (left panel, scale bars $=40 \mu \mathrm{m}$ ) and inoculated with $B$. graminis fsp. hordei. $15 \mathrm{~h}$ post-inoculation (hpi), sites of attempted fungal penetration and additional GFP-based fluorescence (confirming successful expression of $P M R 4-G F P$ or $G F P$ ) were identified by cLSM. Powdery mildew conidia were stained with propidium iodide. Arrows indicate GFP fluorescence (right panel, scale bars $=10 \mu \mathrm{m}$ ). agt: appressorial germ tube, $\mathrm{c}$ : conidium, ng: not germinated. Micrographs in the right panel are representative for sites used for quantification of penetration success; (b) Quantification of host cell entry determined by haustorium formation per conidium 15 hpi. Penetration success in Agrobacterium-infiltrated leaves compared between all cells and those showing a GFP signal (indicator of successful PMR4-GFP or GFP expression). Non-infiltrated leaves served as control. ${ }^{*} P<0.05$, Tukey's test. Error bars represent standard error of the mean, and $n=50$ of 4 independent leaves. A repeat experiment gave similar results. of Glucose [3]. Based on the available barley genome data [22], it would be possible to identify those barley callose synthases that have the highest homology to the stress-induced callose synthase PMR4 from A. thaliana. The identified callose synthase genes would be good candidates for an overexpression in barley and $A$. thaliana. This could help to further elucidate whether the observed resistance to powdery mildew in A. thaliana and barley is facilitated only by PMR4. The result would support the evaluation of possible molecular breeding strategies for improved powdery mildew resistance in crops, which may only include the callose synthase PMR4 from A. thaliana or additional, species-specific callose synthases.

\section{ACKNOWLEDGEMENTS}

Funding was provided in part by a postdoctoral research fellowship from the Deutsche Forschungsgemeinschaft (C.A.V.), the German Federal Ministry of Education and Research (BMBF, FKZ 0315521A, C.A.V.), and the Energy Biosciences Institute (S.C.S. and C.A.V.).

\section{REFERENCES}

[1] Stone, B.A. and Clarke, A.E. (1992) Chemistry and boilogy of $(1 \rightarrow 3)-\beta$-glucans. La Trobe University Press, Bundoora.

[2] Aspinall, G.O. and Kessler, G. (1957) The structure of callose from the grape vine. Chemistry and Industry, London.

[3] Ellinger, D., Naumann, M., Falter, C., Zwikowics, C., Jamrow, T., Manisseri, C., Somerville, S.C. and Voigt, C.A. (2013) Elevated early callose deposition results in complete penetration resistance to powdery mildew in Arabidopsis. Plant Physiology, 161, 1433-1444. doi:10.1104\%2Fpp.112.211011

[4] Verma, D.P. and Hong, Z. (2001) Plant callose synthase complexes. Plant Molecular Biology, 47, 693-701. doi:10.1023\%2FA\%3A1013679111111

[5] Hong, Z., Zhang, Z., Olson, J.M. and Verma, D.P.S. (2001) A novel UDP-glucose transferase is part of the callose synthase complex and interacts with phragmoplastin at the forming cell plate. Plant Cell, 13, 769-780. doi:10.1105/tpc.13.4.755

[6] Dong, X., Hong, Z., Chatterjee, J., Kim, S. and Verma, D. (2008) Expression of callose synthase genes and its connection with $N p r 1$ signaling pathway during pathogen infection. Planta, 229, 87-98. doi:10.1007\%2Fs00425-008-0812-3

[7] Voigt, C.A., Schäfer, W. and Salomon, S. (2006) A comprehensive view on organ-specific callose synthesis in wheat (Triticum aestivum L.): Glucan synthase-like gene expression, callose synthase activity, callose quantification and deposition. Plant Physiology and Biochemistry, 44, 242-247. doi:10.1016/j.plaphy.2006.05.001

[8] Jacobs, A.K., Lipka, V., Burton, R.A., Panstruga, R., Strizhov, N., Schulze-Lefert, P. and Fincher, G.B. (2003) 
An Arabidopsis callose synthase, GSL5, is required for wound and papillary callose formation. Plant Cell, 15, 2503-2513. doi:10.1105/tpc.016097

[9] Nishimura, M.T., Stein, M., Hou, B.H., Vogel, J.P., Edwards, H. and Somerville, S.C. (2003) Loss of a callose synthase results in salicylic acid-dependent disease resistance. Science, 301, 969-972. doi:10.1126/science.1086716

[10] Consonni, C., Bednarek, P., Humphry, M., Francocci, F., Ferrari, S., Harzen, A., Ver Loren van Themaat, E. and Panstruga, R. (2010) Tryptophan-derived metabolites are required for antifungal defense in the Arabidopsis mlo2 mutant. Plant Physiology, 152, 1544-1561. doi:10.1104/pp.109.147660

[11] Bayles, C.J., Ghemawat, M.S. and Aist, J.R. (1990) Inhibition by 2-deoxy-D-glucose of callose formation, papilla deposition, and resistance to powdery mildew in an $\mathrm{ml}-\mathrm{o}$ barley mutant. Physiological and Molecular Plant Pathology, 36, 63-72. doi:10.1016/0885-5765(90)90092-C

[12] Zeyen, R.J., Kruger, W.M., Lyngkjær, M.F. and Carver, T.L.W. (2002) Differential effects of D-mannose and 2-deoxy-D-glucose on attempted powdery mildew fungal infection of inappropriate and appropriate Gramineae. Physiological and Molecular Plant Pathology, 61, 315323. doi:10.1006/pmpp.2003.0444

[13] Naumann, M., Somerville, S.C. and Voigt, C.A. (2013) Differences in early callose deposition during adapted and non-adapted powdery mildew infection of resistant Arabidopsis lines. Plant Signaling \& Behavior, 8, e24408. http://www.landesbioscience.com/journals/psb/article/24 $\underline{408 /}$

[14] Dean, R., Van Kan, J.A., Pretorius, Z.A., HammondKosack, K.E., Di Pietro, A., Spanu, P.D., Rudd, J.J., Dickman, M., Kahmann, R., Ellis, J., et al. (2012) The top 10 fungal pathogens in molecular plant pathology. Molecular Plant Pathology, 13, 414-430. doi:10.1111/j.1364-3703.2011.00783.x

[15] Horwitz, B.A., Sharon, A., Lu, S.W., Ritter, V., Sandrock, T.M., Yoder, O.C. and Turgeon, B.G. (1999) A G protein alpha subunit from Cochliobolus heterostrophus involved in mating and appressorium formation. Fungal Genetics and Biology, 26, 19-32. doi:10.1006/fgbi.1998.1094

[16] Zabbai, F., Jarosch, B. and Schaffrath, U. (2004) Overexpression of chloroplastic lipoxygenase $R C I 1$ causes $P R 1$ transcript accumulation in transiently transformed rice. Physiological and Molecular Plant Pathology, 64, 37-43. doi:10.1016/j.pmpp.2004.04.004

[17] Stein, M., Dittgen, J., Sanchez-Rodriguez, C., Hou, B.H., Molina, A., Schulze-Lefert, P., Lipka, V. and Somerville, S. (2006) Arabidopsis PEN3/PDR8, an ATP binding cassette transporter, contributes to nonhost resistance to inappropriate pathogens that enter by direct penetration. Plant Cell, 18, 731-746. doi:10.1105/tpc.105.038372

[18] Clark, T.A., Zeyen, R.J., Smith, A.G., Bushnell, W.R., Szabo, L.J. and Vance, C.P. (1993) Host response gene transcript accumulation in relation to visible cytological events during Erysiphe graminis attack in isogenic barley lines differing at the Ml-a locus. Physiological and Molecular Plant Pathology, 43, 283-298. doi:10.1006/pmpp.1993.1058

[19] Paredez, A.R., Somerville, C.R. and Ehrhardt, D.W. (2006) Visualization of cellulose synthase demonstrates functional association with microtubules. Science, 312, 1491-1495. doi:10.1126/science.1126551

[20] Seeholzer, S., Tsuchimatsu, T., Jordan, T., Bieri, S., Pajonk, S., Yang, W., Jahoor, A., Shimizu, K.K., Keller, B. and Schulze-Lefert, P. (2010) Diversity at the Mla powdery mildew resistance locus from cultivated barley reveals sites of positive selection. Molecular Plant-Microbe Interactions, 23, 497-509. doi:10.1094/MPMI-23-4-0497

[21] Böhlenius, H., Morch, S.M., Godfrey, D., Nielsen, M.E. and Thordal-Christensen, H. (2010) The multivesicular body-localized GTPase ARFA1b/1c is important for callose deposition and ROR2 syntaxin-dependent preinvasive basal defense in barley. Plant Cell, 22, 3831-3844. doi:10.1105/tpc. 110.078063

[22] Mayer, K.F., Waugh, R., Brown, J.W., Schulman, A., Langridge, P., Platzer, M., Fincher, G.B., Muehlbauer, G.J., Sato, K., Close, T.J., et al. (2012) A physical, genetic and functional sequence assembly of the barley genome. Nature, 491, 711-716. doi:10.1038/nature11543 